\title{
A new approach to blue rubber bleb nevus syndrome: the role of capsule endoscopy and intra-operative enteroscopy
}

\author{
Marcela Kopáčová · Ilja Tachecí · Jaroslav Koudelka • \\ Miroslava Králová · Stanislav Rejchrt · Jan Bureš
}

Accepted: 27 November 2006/Published online: 5 January 2007

(C) Springer-Verlag 2006

\begin{abstract}
Blue rubber bleb nevus syndrome (BRBNS) is a rare vascular malformation disorder with cutaneous and visceral lesions frequently associated with serious, even fatal bleeding and anemia. The syndrome is considered to be autosomaly predominantly inherited. Intra-operative enteroscopy (IOE) is the best method of identification of all lesions (particularly the small ones, less than $3 \mathrm{~mm}$ ) and treatment by endoscopic electro-coagulation or surgical excision. Capsule wireless endoscopy is optimal for screening before the IOE and for monitoring the effect of therapy (in patients with BRBNS). We report two cases of BRBNS. Anemia, gastrointestinal bleeding, gastroin-
\end{abstract}

\footnotetext{
M. Kopáčová $(\bowtie)$ · I. Tachecí · S. Rejchrt · J. Bureš

2nd Department of Medicine,

Charles University in Praha,

Faculty of Medicine at Hradec Kralove,

University Teaching Hospital, Sokolska 581,

Hradec Kralove 500 05, Czech Republic

e-mail: kopacmar@fnhk.cz

I. Tachecí

e-mail: tacheci@gmail.com

S. Rejchrt

e-mail: rejchrt@lfhk.cuni.cz

J. Bureš

e-mail: bures@lfhk.cuni.cz

J. Koudelka · M. Králová

Department of Pediatric Surgery,

Charles University in Praha,

Faculty of Medicine at Hradec Kralove,

University Teaching Hospital, Sokolska 581,

Hradec Kralove 500 05, Czech Republic

e-mail: koudelka@fnhk.cz

M. Králová

e-mail: kralova@fnhk.cz
}

testinal malformations and multifocal venous malformations of the skin were present in both of our cases. Gastrointestinal lesions were identified by gastroscopy, colonoscopy and capsule endoscopy. The multiple venous malformations were treated partly by endoscopic electro-coagulation (lesions up to $4 \mathrm{~mm}$ in diameter) and by wedge resection. Both of our patients were 12year-old girls at the time of operation. In the first patient 31 venous malformations of the small bowel were coagulated, two were resected by the surgeon. In the second patient 20 lesions were coagulated endoscopically and another 31 nevi were resected during an $8 \mathrm{~h}$ procedure. The first girl is doing fine 4 years after the procedure, the second was allowed home 2 weeks after the procedure in excellent condition. IOE is a unique method of small bowel investigation and concurrently provides a solution for pathological findings. Capsule endoscopy is a feasible non-invasive screening procedure. We believe that a radical eliminatory approach by means of combined surgery and IOE is indicated for the BRBNS to prevent ongoing gastrointestinal bleeding.

Keywords Intra-operative Peri-operative . Enteroscopy - Blue rubber bleb - BRBNS - Capsule endoscopy

\section{Introduction}

Blue rubber bleb nevus syndrome (BRBNS) is a rare congenital disorder presenting with multifocal venous malformations. These most commonly involve the skin and gastrointestinal tract, but can also affect the brain, kidneys, lungs, eyes, bones and other organs. 
Hemostatic abnormalities due to consumption coagulopathy and thrombocythemia were referred as well. BRBNS affects all races, both sexes, adults and children. The lesions are present in childhood but can develop later in life. They are usually blue colored and easily compressible with light palpation.

The most important clinical problem for these patients is the management of acute or chronic bleeding from the multiple alimentary vascular malformations with the small intestine usually involved. The bleeding is acute, presenting as hematemesis, melena, or rectal bleeding. Unless treated radically, patients with BRBNS develop anemia from chronic gastrointestinal bleeding and require lifelong treatment with iron and blood transfusions. No malignant change of the lesions has been reported so far. Infrequent complications of the gastrointestinal malformations are volvulus, intussusception and intestinal infarction.

The cause of syndrome is still unknown. An autosomal dominant expression has been reported in several families, although most cases have no apparent hereditary pattern. The syndrome may possibly be subject to dominant inheritance due to a gene mutation mapped on the short arm of chromosome 9.

BRBNS was probably first described in 1860 by Gascoyen (association between cavernous hemangiomas of the skin and multiple similar lesions in the gastrointestinal tract, which subsequently caused gastrointestinal bleeding); however, it was described in detail by William Bean [1] in 1958 and thus was named Bean syndrome.

\section{Case reports}

We report two cases of BRBNS treated in 2002 (Case 1) and 2006 (Case 2). Pre-operative diagnosis was performed only in the second case using gastroscopy, colonoscopy and capsule wireless endoscopy.

\section{Case 1}

This patient was a 12-year-old girl at the time of the procedure. The mother of the patient had hepatic hemangioma, otherwise the family history was negative.

At birth, the patient displayed vascular lesion of the right sole and toe, other venous malformations (on her right knee and in lumbar area) appeared later on. She underwent operation elsewhere because of these lesions. Her condition rapidly deteriorated at the age of 12. She was suddenly exhausted, collapsed and had to be admitted to hospital elsewhere. Hemoglobin at admission was $55 \mathrm{~g} / \mathrm{L}$. The patient suffered from melena; three units of blood transfusion had to be administered. An abdominal ultrasound, CT scan of the brain, neurological consultation, gastroscopy and colonoscopy were performed with normal findings. The girl was a candidate for intra-operative enteroscopy (IOE) because of a suspected source of gastrointestinal bleeding in the small intestine. Therefore she was transferred to our Department of Pediatric Surgery.

Two foci of extravasation were found located in the small intestine using scintigraphy with autologous tagged erythrocytes. Based on this information we decided to perform IOE. The patient did not require further blood transfusions before the surgery.

Altogether 31 venous malformations up to $4 \mathrm{~mm}$ in diameter were coagulated endoscopically by means of electro-coagulation using a BICAP Probe during the procedure, only additional two lesions (10 and $12 \mathrm{~mm}$ in diameter) were resected by surgeon after intraoperative enteroscopy in the same anesthesia. The endoscopic part of IOE lasted $2 \mathrm{~h}$-all the surgery took $4 \mathrm{~h}$. The girl has had no anemia and no signs of gastrointestinal bleeding so far.

\section{Case 2}

The patient was also a 12-year-old girl at the time of the procedure. Her family history was negative. A vascular lesion of the right cheek was present at the time of her birth. An angiography of this lesion was indicated 2 years later aimed at possible embolization. That idea had to be abandoned because of anastomosis with the internal carotid artery. The patient started with conservative therapy (corticosteroids and interferon alpha). Despite the therapy, she had to undergo an operation, because the lesion became enlarged and oppressed her upper jaw. The patient started with severe anemia at the age of eight, she received several units of blood transfusions and started to be treated by oral iron tablets. Not until the age of 11 was gastrointestinal bleeding (melena) first noticed. A gastroscopy was performed elsewhere finding antral venous malformation. Colonoscopy showed four similar lesions within the colon. There were several hemangiomas of the liver at CT scan. The venous malformation of the right cheek persisted and numerous new subcutaneous lesions had appeared during her life. However, anemia rapidly progressed and the need for transfusions increased. The amount of transfusion was estimated at several tens.

With regards to this setback, the girl was admitted to our Department of Pediatric Surgery. Hemoglobin at the admission was $110 \mathrm{~g} / \mathrm{L}$ and so she did not require 


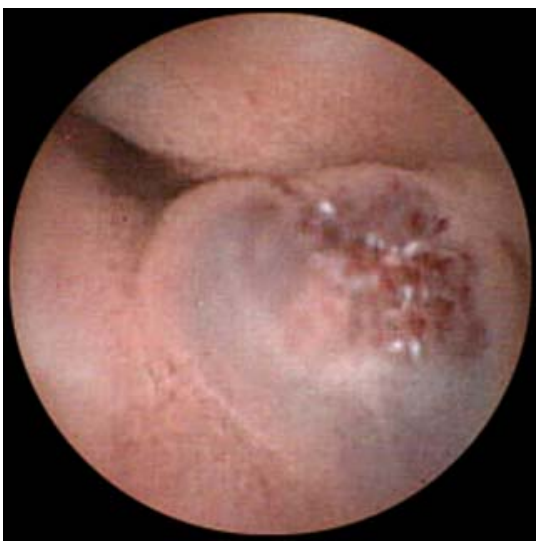

Fig. 1 Capsule wireless endoscopy. Typical appearance of blue rubber bleb nevus in the ileum

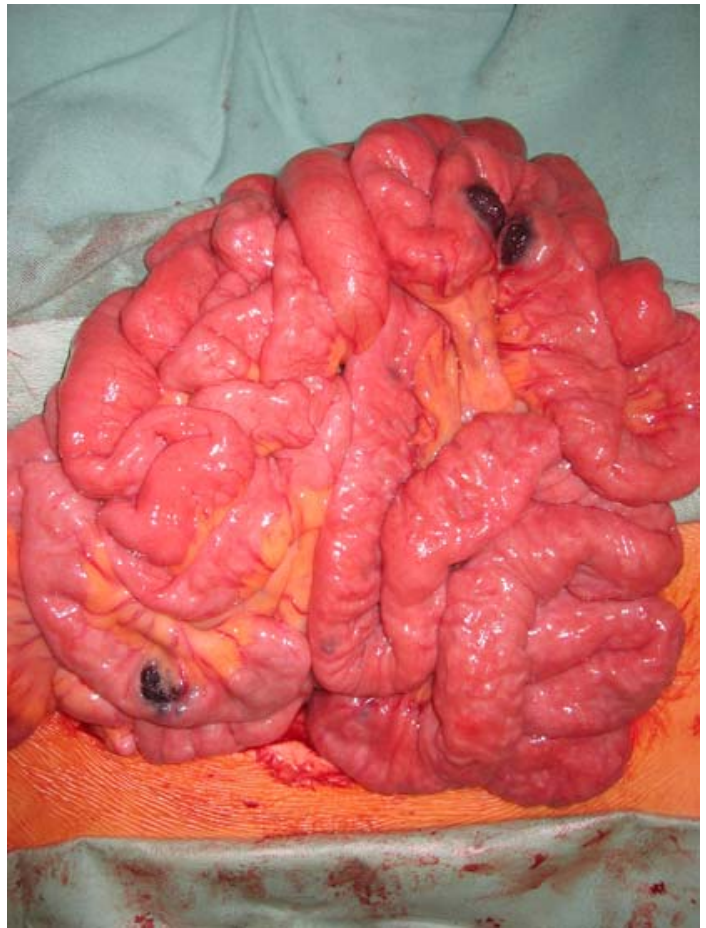

Fig. 2 View of open abdominal cavity_-blue rubber blebs in the small intestine. The transmural nature of lesions is nicely seen

further blood transfusions. A capsule wireless endoscopy was performed and revealed BRBNS, more than 20 typical venous malformations were recognized at the capsule endoscopy (see Fig. 1).

Elective IOE was subsequently carried out (see Figs. 2, 3), 20 venous malformations of the small intestine (in diameter up to $4 \mathrm{~mm}$ ) were coagulated in an endoscopic manner using a BICAP Probe and another 31 lesions (up to diameter of $15 \mathrm{~mm}$ ) were marked by suture and all of them were removed by the surgeon (using wedge resection) after IOE in the same

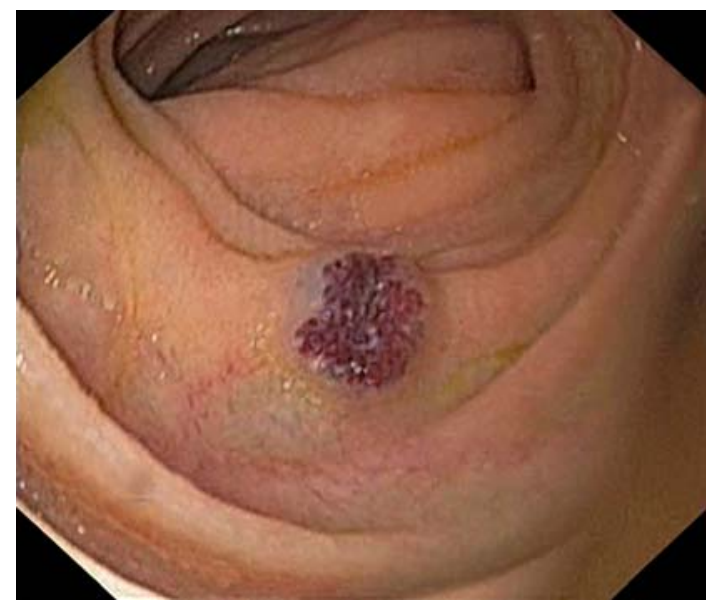

Fig. 3 Intra-operative enteroscopy. Blue rubber bleb nevus of the distal jejunum

anesthesia. Two malformations of the colon and three subcutaneous malformations (in the mental region and both metatarsi) were resected at the same time. The whole procedure took $8 \mathrm{~h}$ altogether, the endoscopic part took $3 \mathrm{~h}$. The patient was allowed home 2 weeks after the procedure in excellent condition.

We had no immediate or procedure-related complications. No postoperative problems occurred and both the girls are completely healthy without further bleeding after a follow-up period of 4 years and 6 months, respectively.

\section{Discussion}

BRBNS is a rare disorder. A MEDLINE search yielded about 200 case reports published till 2003 [2]. According to the literature some cases have been described with an autosomal dominant pattern of inheritance, but most cases are sporadic [3-5]. In our two patients we did not find any other relatives with BRBNS. In most patients (as well as in ours) subcutaneous lesions are found congenitally and with advancing age they may persist or enlarge [5]. Therapy of BRBNS is aimed at management of complications. Cutaneous lesions usually do not bleed; surgical therapy, sclerotherapy or embolization provided a good cosmetic result for the most parts. Bleeding vascular lesions spread out over the gastrointestinal tract are the worst. In the absence of massive bleeding, a conservative treatment is sufficient. Conservative therapy consists mostly of iron supplementation and/or blood transfusions. In pediatric patients, there have been reports of the use of corticosteroids, antifibrinolytic agents, high-dose i. v. gamma globulin and interferon 
alpha. Overall, results with the use of these drugs have not been encouraging [6]. Long-term use of octreotide was found to reduce blood loss from BRBNS or other vascular gastrointestinal lesions [7, 8]. All statements are based on case reports. Fishman et al. [9] treated ten patients with BRBNS. The multiple malformations were removed by a combination of wedge resection, polypectomy, suture-ligation, segmental bowel resection and band ligation [9]. They believe (as we do) that an aggressive excisional approach is indicated for the venous anomalies, which cause gastrointestinal bleeding in BRBNS [9]. In contrast to Fishman, we are convinced that endoscopic polypectomy or band ligation are high-risk procedures in patients with BRBNS - a number of lesions are transmural ones and there is a high risk of perforation. Therefore doubleballoon enteroscopy is not an acceptable method for patients with BRBNS and will not replace IOE in this indication [10]. According to Shimada et al. endoscopic sclerotherapy is ineffective and leads to the development of ulcerations, strictures, and extravasation of the sclerosing agent [11] and we do entirely agree with this opinion.

In our two cases, multiple venous malformations were treated in a combined way, partly by endoscopic electro-coagulation and by full-thickness wedge excision. There was no need for any bowel resection in our two patients. We consider IOE as the best method for patients with BRBNS. Smaller lesions are detectable only by endoscopy, merely two blebs were seen in the former and ten in the latter patient by the naked eye, the remainder of malformations (72 in total) were found by endoscopy. IOE has been accepted as the ultimate diagnostic and/or therapeutic procedure for

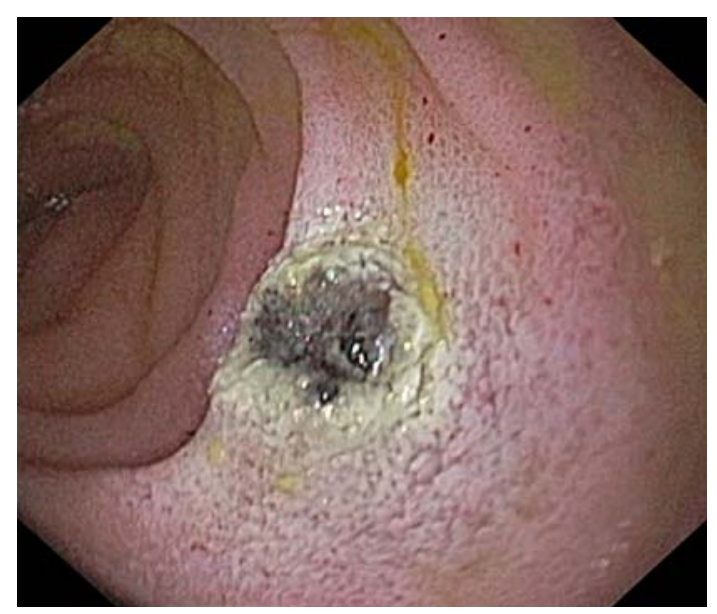

Fig. 4 Intra-operative enteroscopy. A blue rubber bleb nevus after endoscopic electro-coagulation (using a BICAP Probe). The same place as seen in Fig. 3 the complete investigation of the small bowel. It makes it possible to immediately solve pathological findings by endoscopic or surgical means $[10,12]$. We prefer a BICAP Probe for electro-coagulation (see Fig. 4) during the IOE, however argon plasma coagulation and laser photocoagulation are comparable tools $[2,13]$.

In accordance with literature we use capsule wireless endoscopy prior to IOE to specify the indication for the procedure $[14,15]$. Capsule endoscopy may also be a useful tool for monitoring the effects of therapy in patients with BRBNS $[15,16]$. We have not performed control capsule wireless endoscopy in our two patients yet, because both of the girls are in a good health.

IOE for the treatment of bleeding intestinal blebs and capsule wireless endoscopy for screening and monitoring of the patients seem to be a gold standard for this disease alone.

Acknowledgments The study was supported by research project: MZO 00179906 from the Ministry of Health, Czech Republic.

\section{References}

1. Bean WB (1958) Blue rubber bleb nevi of the skin and gastrointestinal tract. In: Thomas CC (ed) Vascular spiders and related lesions of the skin. Charles $\mathrm{C}$ Thomas, Springfield, pp 178-185

2. Dobru D, Seuchea N, Dorin M, Careianu V (2004) Blue rubber bleb nevus syndrome: case report and literature review. Rom J Gastroenterol 13:237-240

3. Giordano C, Battagliese A, di Gioia CRT, Campagna D, Benedetti F, Travaglini C, Gallo P, d'Amati G (2004) Blue rubber bleb nevus syndrome and pulmonary hypertension: an unusual association. Cardiovasc Pathol 13:317-322

4. Arguedas MR, Wilcox CM (1999) Blue rubber bleb nevus syndrome. Gastrointest Endosc 50:544

5. Chang EL, Rubin PAD (2002) Hemangiomas and blue rubber nevus syndrome. Ophthalmology 109:537-541

6. Beck PL, Aspinall AI, Kilvert VM, Dort J (2002) Blue rubber bleb nevus syndrome. Gastrointest Endosc 56:598600

7. Gonzalez D, Elizondo BJ, Haslag S, Buchanan G, Burdick JS, Guzzetta PC, Hicks BA, Andersen JM (2001) Chronic subcutaneous octreotide decreases gastrointestinal blood loss in blue rubber-bleb nevus syndrome. J Pediatr Gastroenterol Nutr 33:183-188

8. Blich M, Fruchter O, Edelstein S, Edoute Y (2003) Somatostatin therapy ameliorates chronic and refractory gastrointestinal bleeding caused by diffuse angiodysplasia in a patient on anticoagulation therapy. Scand J Gastroenterol 38:801-803

9. Fishman SJ, Smithers CJ, Folkman J, Lund DP, Burrows PE, Mulliken JB, Fox VL (2005) Blue rubber bleb nevus syndrome: surgical eradication of gastrointestinal bleeding. Ann Surg 241:523-528

10. Kopáčová M, Bureš J, Vykouřil L, Hladík P, Šimkovič D, Jon B, Ferko A, Tachecí I, Rejchrt S (accepted for 
publication 2006) Intra-operative enteroscopy. Ten year's experience at a single tertiary center. Surg Endosc (in press)

11. Shimada S, Namikawa K, Maeda K, Obata S, Ikei S, Mizutani J, Ogawa M (1997) Endoscopic polypectomy undek laparotomy throughout the alimentary tract for a patient with blue rubber bleb nevus syndrome. Gastrointest Endosc 45:423-427

12. Kopáčová M, Bureš J, Rejchrt S, Široký M, Bedrna J, Ferko A, Hajžman Z, Hladík P, Holeček T, Hroch T, Chobola M, Jandík P, Jaroš E, Jon B, Kabeláč K, Leško M, Mergancová J, Pospíśil I, Př́iborský J, Šimkovič D, Špaček V, Trlica J, Vykouril L (2003) Intraoperative enteroscopy: personal experience from 1995 to 2002 (in Czech). Čas Lék Česk 142:303-306
13. Ng WT, Kong CK (2003) Argon plasma coagulation for blue rubber bleb nevus syndrome in a female infant. Eur J Pediatr Surg 13:137-139

14. Pennazio M (2005) Small-intestinal pathology on capsule endoscopy: spectrum of vascular lesions. Endoscopy 37:864869

15. De Bona M, Bellumat A, De Boni M (2005) Capsule endoscopy for the diagnosis and follow-up of blue rubber bleb nevus syndrome. Dig Liver Dis 37:451-453

16. Fish L, Fireman Z, Kopelman Y, Sternberg A (2004) Blue rubber bleb nevus syndrome: small-bowel lesions diagnosed by capsule endoscopy. Endoscopy 36:836 